ORGANIZATIONAL BEHAVIOR AND HUMAN PERFORMANCE 8, 185-200 (1972)

\title{
Time Pressure and Performance of Scientists and Engineers: A Five-Year Panel Study ${ }^{1}$
}

\author{
Frank M. ANDREWs \\ Institute for Social Research, University of Michigan
}

$A N D$

GEORGe F. FARRIS

Sloan School of Management, Massachusetts Institute of Technology

\begin{abstract}
Time pressure experienced by scientists and engineers predicted positively to several aspects of performance including usefulness, innovation, and productivity. Higher time pressure was associated with above average performance during the following five years, even when supervisory status, education, and seniority were controlled. Performance, however, did not predict well to subsequent reports of time pressure, suggesting a possible causal relationship from pressure to performance. High performing scientists also desired more pressure. Innovation and productivity (but not usefulness) were low if the pressure experienced was markedly above that desired. The five-year panel data derived from approximately. 100 scientists in a NASA laboratory. Some theoretical and practical implications of the results are discussed.
\end{abstract}

Time pressure is often cited as a problem experienced by members of formal organizations. Moreover, it is an administratively interesting factor, since it is one over which management may have substantial influence.

The folklore about managing scientific laboratories includes two competing approaches to the management of time pressure: (1) provide professional staff with an unhurried "academic" environment, and (2) establish tight schedules and deadlines to avoid the Parkinsonian nightmare of work expanding to meet the time available.

What is the relationship between time pressure and scientific performance? Does time pressure tend more to predict performance or to be predicted by past performance? What characteristics of a scientist's working

${ }^{1}$ This research was supported by Grant NGR23-005-395 from the National Aeronautics and Space Administration. The authors are grateful for helpful comments from Donald C. Pelz, John R. P. French, Jr., and Raymond Faith, and for the technical assistance of Marita Di Lorenzi.

Copyright (C) 1972 by Academic Press, Inc.

All rights of reproduction in any form reserved. 
environment are associated with his sense of time pressure? It is to these questions that the present article is addressed.

Despite the acknowledged importance of time pressure in organizations, surprisingly little research has been directly devoted to it. In group interviews about job pressures, Hall and Lawler (1971) found that a sense of time pressure was mentioned in more than three-quarters of the 22 scientific laboratories they studied. Of all the different kinds of pressures mentioned by the scientists and engineers in these interviews, "by far the most widely felt pressure was time (p. 67)." Although some of the other pressures did relate to laboratory performance as rated by the laboratory manager, no significant relationship was found between time pressure and performance.

The Hall and Lawler results were foreshadowed to some extent by two sets of findings reported by $\mathrm{Pel} z$ and Andrews (1966). One set indicated that scientists and engineers were especially likely to be low performers if they worked under conditions of loose coordination and high autonomy-a situation under which many kinds of job pressures might be expected to be minimal. Pelz and Andrews suggested that the low performance might be a result of low stimulation and/or motivation. The notion agrees well with that advanced by Hall and Lawler, who also suggested that motivational factors might account for the observed relationships between pressure and performance. Another set of findings by Pelz and Andrews indicated that scientific performance tended to be greater for those scientists and engineers who worked a nine- or ten-hour day, on the average; those who averaged only a standard eight-hour day or an eleven-hour day tended to perform at lower levels. To the extent that working hours are dictated by time pressure, these findings suggest a curvilinear relationship between time pressure and performance.

Related to time pressure is the concept of "overload." Kahn, et al. (1964) consider overload as "one of the dominant forms of role conflict...., which can be thought of as a conflict among legitimate tasks, or a problem in the setting of priorities (p. 380)."

Overload could be regarded as a kind of inter-sender conflict in which various role senders may hold quite legitimate expectations that a person perform a wide variety of tasks, all of which are mutually compatible in the abstract. But it may be virtually impossible for the focal person to complete all of them within given time limits (p.20).

Recent studies of colleague roles in a scientific laboratory indicate that role overload may be one characteristic of a scientist's working environment which is related to a sense of time pressure. Farris (1971) and Swain (1971) found that scientists who were named by more of their colleagues as helpful in their technical problem solving (a situation likely 
to engender inter-sender role conflict) experienced a greater feeling of time pressure.

Miller (1960) considers responses to information input overload, another factor which may be related to feelings of time pressure. Some of these are clearly dysfunctional in the organizational context - failing to process some of the information, processing some of the information incorrectly, or escaping from the task. Others may be functional or dysfunctional, depending on other factors-queuing, filtering, approximation, or employing multiple channels. As Katz and Kahn (1966) point out,

people are likely to process the familiar elements in a message, which they readily understand and which do not constitute major problems for them. Under time pressures the parts of the communication difficult to decode are neglected for the more easily assimilated parts, even though the former may be more eritical for the organization (p. 232).

Taken together, this research and theory on overload suggest that time pressure and overload are related. Role overload may be a source of time pressure, and responses to information overload, experienced by the scientist or engineer as time pressure, may well be dysfunctional for his performance.

Given this slim body of research and theory related to time pressure and performance, it is not surprising that the folklore about managing the time pressure of scientists is so contradictory. In the present study we shall attempt to resolve some of these contradictions. Specifically we shall consider the following questions:

1. How much time pressure is experienced by scientists and engineers in a government laboratory? How much time pressure do they consider optimum?

2. How does experienced time pressure relate to the scientist's performance as measured by his usefulness to his organization? Is time pressure related more strongly to the scientist's past usefulness or his subsequent usefulness?

3. How does experienced time pressure relate to the scientist's performance as measured by the innovation and productiveness of his work? Is time pressure related more strongly to the scientist's past innovation and productiveness or his subsequent innovation and productiveness?

4. How does experienced time pressure relate to these five characteristics of the scientist - freedom provided by his supervisor, preferences for working alone, involvement in technical work, time spent on administrative duties, and number of close colleagues?

5. How does performance relate to three other aspects of time pressure-optimal time pressure, the difference between experienced and 
optimal pressure, and the "span" of different pressures experienced during a typical month's work?

\section{METHOD}

The present study was conducted in a NASA research division where scientists and engineers were exploring the effects of extreme physical conditions on various materials. Their work involved a mixture of research, development, and technical services.

The first wave of data was collected in 1965 (Time 1) from 117 scientists and engineers. The second wave occurred five years later (Time 2), and was based on 118 professional personnel, 78 of whom had also participated in 1965. At both Time 1 and 2, each participant completed a lengthy questionnaire and his performance was evaluated by judges selected from among other professionals in the lab.

\section{Performance Measures}

The performance criteria included the following:

Innovation - the extent the man's work had "increased knowledge in his field through lines of research or development which were useful and new,"

Productiveness-the extent the man's work had "increased knowledge along established lines of research or development or as extensions or refinements of previous lines," and

Usefulness-the extent the man's work had been "useful or valuable in helping his $\mathrm{R} \& \mathrm{D}$ organization carry out its responsibilities."

These qualities were independently assessed by an average of 4.4 judges at Time 1, and 7.6 at Time 2, each of whom claimed to be familiar with the man's work. Each judge ranked the scientists with whom he was familiar on the basis of their work over the preceeding five years. Approximately two-thirds of the judges were supervisors (the man's own chief might be among them), and one-third were senior-level nonsupervisors. Since the judges showed reasonably good agreement, their evaluations were combined into a single percentile score (on each quality) for each respondent. ${ }^{2}$

As is usually found for scientists and engineers, these performance measures varied according to the respondent's length of experience, seniority, and formal training (Pelz \& Andrews, 1966). Since these effects might mask the relationships of interest, all performance measures were adjusted by adding or subtracting appropriate constants to remove such back-

${ }^{2}$ Based on the average inter-judge agreement and the average number of judges, the reliability of the performance ratings was estimated to be .95 at Time 1 and .88 at Time 2, using the Spearman-Brown formula (Guilford, 1954). 
ground effects. ${ }^{3}$ Thus, the final performance measures expressed how well or poorly each person performed relative to others with similar experience and training.

The interrelationships among these various criteria of performance were about as expected. All were substantially related to one another (correlations ranged .7 to .8 at both Times 1 and 2), with innovation being least similar to the others.

\section{Measures of Time Pressure}

The time pressure experienced by the respondent was assessed by the following question:

Technical jobs sometimes involve working under time pressures exerted by other people-results are needed urgently, there are deadlines to be met, etc. In a typical month about what proportion of your time is spent working under the following amounts of pressure? (Five categories of pressure were listed, from "Relaxed-no pressure at all" to "Extreme pressure-I'm behind on important deadlines." The respondent entered the percentage of his time spent under each amount of pressure.)

Optimum time pressure was measured by a subsequent question which asked the respondent to indicate what he thought would be the optimum proportion of his time spent under each level of pressure in order for him to make his best contributions. From this basic information four scales were constructed:

(1) Typical level of time pressure experienced; ${ }^{4}$

(2) Amount of time pressure the respondent felt would be optimal;"

(3) Difference between the actual and optimum; ${ }^{5}$ and

(4) "Span" or "range" of time pressures actually experienced.5 (A person who said nearly all his work occurred under a single level of pressure had a low span; those who experienced widely different pressures had a high span.)

${ }^{3}$ The procedures for collecting, combining, and adjusting the performance measures used in this study were highly similar to those more fully described in Pelz and Andrews (1966). However, experience was not considered separately from seniority in adjusting the performance measures collected at Time 2.

${ }^{4}$ This scale was based on the median amount of pressure indicated by each scientist (e.g., one who experienced "slight" pressure during 30\% of his work time, "moderate" pressure for $40 \%$, and "great" pressure for $30 \%$ woutd be grouped with others whose median also fell in the "moderate" range). The resulting distribution was unimodal and reasonably symmetric.

${ }^{5}$ This scale was transformed to yield a reasonably symmetric unimodal distribution appropriate for analysis using statistics such as the Pearson correlation coefficient, 


\section{Other Variables}

In addition to the performance and time pressure variables, the questionnaire asked about a wide range of other phenomena including motivation levels, communication with colleagues, role of the technical supervisor, and attitudes toward work. These other variables contributed to insights about the relationship of time pressure to performance and will be mentioned at appropriate places later in the article.

\section{RESULTS}

Distribution of Time Pressures

The amount of time pressure typically experienced by respondents in this site varied widely (see Table 1). At Time 1, 27\% devoted more than half of their time to activities for which they experienced no sense of urgency. At the other extreme, $8 \%$ said half or more of their time was spent on activities for which there was "great" or "extreme" urgency. The distribution of time pressures was roughly similar at Time 2 to what it was at Time 1, though pressure levels tended to be somewhat lower.

With respect to optimum time pressure, there was again substantial variation between respondents. Almost all wanted at least some pressure, and those who experienced more pressure were generally the ones who also wanted more (correlations between typical and optimum time pressures were .5 at Time 1 and .6 at Time 2 ).

While some respondents experienced more pressures than they felt would be optimal (and some had less pressure than desired), experienced pressure levels were just slightly above optimal levels when averaged across all respondents. In short, these scientists and engineers-in the aggregate-were reasonably well satisfied with respect to the time pressure experienced on their jobs.

TABLE 1

Median Level of Trme Pressure Experienciad (Percent of Respondents)

\begin{tabular}{lcc}
\hline Median level of pressure & Time 1 & Time 2 \\
\hline Relaxed & $27 \%$ & $39 \%$ \\
Slight pressure & 33 & 30 \\
Moderate pressure & 32 & 24 \\
Great pressure & 7 & 7 \\
Fxtreme pressure & 1 & 0 \\
Total & $100 \%$ & $100 \%$ \\
$N$ & $(117)$ & $(118)$ \\
\hline
\end{tabular}




\section{Experienced Time Pressure and Usefulness}

Given the nature of the data, it is possible to examine how the several measures of time pressure-experienced, optimum, deviation of experienced from optimum, and span-related to three distinct aspects of performance-its innovativeness, productiveness, and usefulness. Furthermore, one can examine relationships at one point in time and also "lagged" relationships. For example, one can determine whether experiencing time pressure at Time 1 was predictive of performance levels during the following five years, and whether performance prior to Time 2 was predictive of subsequent feelings of time pressure. ${ }^{b}$

Figure 1 shows the interrelationships among experienced time pressure and judgments of usefulness (adjusted for experience and formal education, as described previously) at Times 1 and 2 .

The most important result occurs in the cross-lagged correlations. Experienced time pressure, measured at Time 1, related +.49 to subsequent usefulness of scientists and engineers (Time 2); however, Time 1 usefulness was virtually unrelated $(+.10)$ to subsequent time pressure. ${ }^{7}$ Interestingly, experienced time pressure related more strongly to subsequent usefulness $(r=.49)$ than it did to usefulness measured at the same time as time pressure ( $r=.32$ at Time $1, .20$ at Time 2$)$.

These results suggest that not only did above-average sense of time pressure characterize the more useful members of a laboratory, but that

${ }^{6}$ The appropriate way to analyze this type of data has been the subject of lively methodological debate in recent years. Campbell and Stanley (1963), and Pelz and Andrews (1964) independently proposed the "cross-lagged panel correlation" technique. Yee and Gage (1968), Duncan (1969), Rozelle and Campbell (1969), Heise (1970), Kenny (1970), Rees (1971), and Sandell (1971) have proposed modifications to the analysis method or to the interpretations which are appropriate. The focus of attention has been on what conclusions about underlying causal dynamics could be drawn on the basis of an observed difference in cross-lagged relationships.

It seems clear that a statistically significant difference between two cross-lagged panel correlations provides strong evidence that the co-variation between two variables is not solely the result of their relationships to some third variable (i.e., a "common factor"). Moreover, Farris (1969c) has argued that a lagged correlation different from zero provides a basis for considering causal hypotheses in dynamic social systems, provided that certain other conditions have been met. Having rejected alternative explanations, certain causal hypotheses may be considered. The choice among these hypotheses will depend on particular assumptions or additional data.

${ }^{\tau}$ The difference between the cross-lagged relationships was statistically significant at the .005 level using the Pearson-Filon test (Peters \& Van Voorhis, 1940).

Heise (1970) has proposed that rather than examining correlations for the crosslagged relationships one should examine path coefficients. The path coefficients turn out to be +.3 and .0 , showing essentially the same pattern as the correlations. 


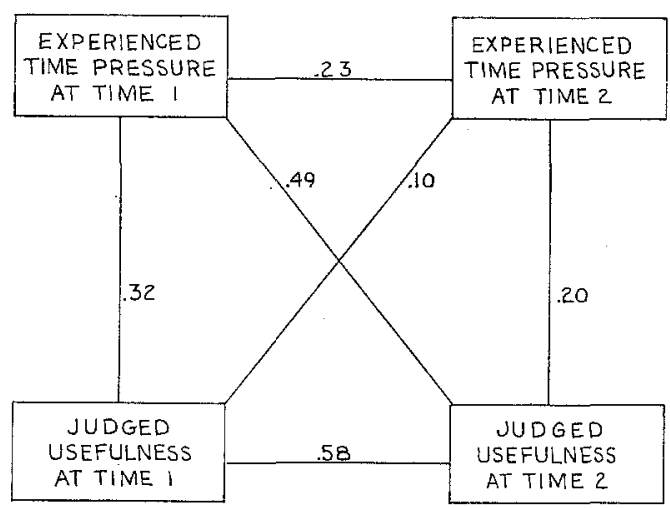

FIG. 1. Relationships among experienced time pressure and usefulness at two time periods (Pearson correlations).

Note.-See "Method" section for numbers of cases.

their sense of time pressure may well have been partially responsible for their higher usefulness. However, it was not the case that scientists and engineers who were judged more useful subsequently found themselves under markedly above-average time pressure. ${ }^{8}$

These findings are in sharp contrast to results reported by Farris $(1969 \mathrm{a}, 1969 \mathrm{~b})$ for a number of other factors. In three industrial laboratories, he found that scientists' job involvement, influence, salary, and number of subordinates each tended to relate more strongly to prior performance than subsequent performance. His findings held with different time lags-when the performance measurement referred to the five years immediately prior to the measurement of the organizational factor (what we are calling "simultaneous" relationships in this panel study) or when there was a five year time lag between the measurement of performance and the measurement of the organizational factors (as in the lagged relationships in the present study).

These findings were sufficiently interesting that a number of additional analyses were run to see whether the time pressure-usefulness connection could be easily explained away. In adjusting the performance measures for differences in training and experience, had some artifact been introduced? No, a parallel analysis on the unadjusted measures showed a highly similar pattern. Could it be attributed to mixing supervisors and nonsupervisors? No, when the analysis was carried out just for people

${ }^{8}$ Figure 1 also shows substantial stability $(r=.58)$ in judgments about a man's usefulness over the five year period, and also some tendency for stability $(r=.23)$ in the amount of time pressure experienced. 
who had been in nonsupervisory roles at both Times 1 and 2 , the same pattern again emerged.

What about the level of time pressure? Was the relationship underlying the positive correlations linear, or did performance tend to drop at the highest levels of pressure? An extensive check showed that all of the relationships depicted in Fig. 1 were essentially linear. Figure 2 shows the two relationships involved in the cross-lagged comparison. The solid line, which corresponds to what we believe to be the underlying causal dynamics, is the most interesting. Note that scientists who indicated (at Time 1) that at least half of their time was spent under "relaxed" conditions scored, on the average, at the 34th percentile with respect to usefulness five years later when compared to others of similar training and experience. In contrast, those few who at Time 1 had said half or more of their work time was spent under "great" pressure, averaged at the 74 th percentile on usefulness five years later. Similarly the dashed line in Fig. 2 shows the essentially linear relationship underlying the +.10 correlation in Fig. 1.

Why then, do these findings differ from the earlier longitudinal relationships reported by Farris $(1969 \mathrm{a}, 1969 \mathrm{~b})$ ? Perhaps "performance feedback loops"-relationships between performance and subsequent characteristics of a scientist's working environment -are in fact stronger in industrial laboratories like those studied by Farris than in government

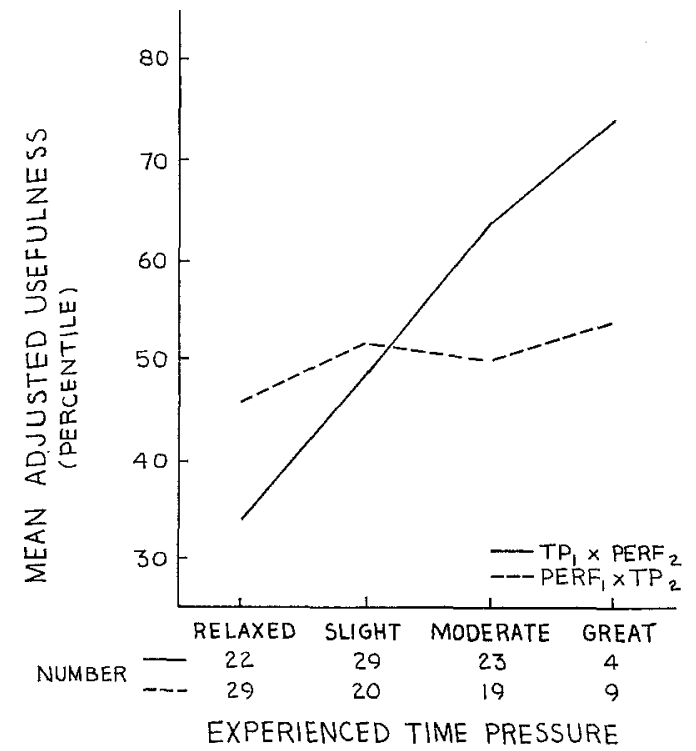

Fig. 2. Mean usefulness related to experienced time pressure. 
TABLE 2

Correlations among Experienced Time Pressure and Two Performance Measures at Times 1 and $2^{a}$

\begin{tabular}{|c|c|c|c|c|c|}
\hline \multirow[b]{2}{*}{$\begin{array}{l}\text { Performance } \\
\text { measure }\end{array}$} & \multicolumn{2}{|c|}{$\begin{array}{l}\text { Cross-lagged } \\
\text { relationships }\end{array}$} & \multicolumn{2}{|c|}{$\begin{array}{l}\text { Simultaneous } \\
\text { relationships }\end{array}$} & \multirow{2}{*}{ 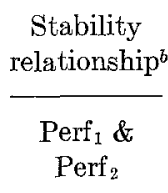 } \\
\hline & $\begin{array}{l}\mathrm{TP}_{1} \& \\
\text { Perf }_{2}\end{array}$ & $\begin{array}{c}\operatorname{Perf}_{1} \\
\& \mathrm{TP}_{2}\end{array}$ & $\begin{array}{l}\operatorname{TP}_{1} \& \\
\operatorname{Perf}_{1}\end{array}$ & $\begin{array}{l}\mathrm{TP}_{2} \& \\
\text { Perf }_{2}\end{array}$ & \\
\hline Productiveness & .21 & .05 & .29 & .09 & .45 \\
\hline Innovation & .25 & -.14 & .23 & .07 & .60 \\
\hline
\end{tabular}

a See "Method" section for numbers of cases.

${ }^{b}$ For stability of time pressure, see Fig. 1.

laboratories such as those in the present study. Or alternatively-unlike involvement, influence, salary, or number of subordinates-time pressure may indeed be a factor which relates more strongly to subsequent performance than to prior performance in scientific laboratories.

\section{Time Pressure, Innovation, and Productiveness}

When analyses parallel to those shown in Fig. 1 were carried out for the other performance measures-judged innovation and judged productiveness-similar patterns were obtained in the cross-lagged correlations, though trends were weaker. Table 2 provides the results.

Looking first at productiveness, one again sees a positive relationship $(r=.21)$ between time pressure and subsequent productiveness, but practically no relationship $(r=.05)$ between productiveness and subsequent time pressure. Again, it would appear that time pressure may have enhanced performance. ${ }^{9}$

Turning next to results for innovativeness, one again encounters a substantial positive difference in the cross-lagged relationships. As before, time pressure was positively related $(r=.25)$ to subsequent performance (innovativeness). But note, also, the mild negative relationship between innovativeness and subsequent time pressure! $!^{10}$ This is particularly intriguing in view of the folklore, mentioned previously, that scientists, par-

${ }^{9}$ This statement is based on the similarity in trends to that observed previously. With the number of cases available this particular cross-lagged differential was statistically significant only at the .15 level. Heise's path coefficients $(.09$ and -.02$)$ showed a pattern similar to that of the cross-lagged correlations. The underlying relationships were essentially linear.

${ }^{10}$ The cross-lagged difference was statistically significant at the .005 level. The Heise path coefficients were .12 and -.20 , again matching the pattern of the crosslagged correlations. Relationships were generally linear. 
ticularly those doing creative work, need a relaxed environment. Among these scientists, those judged more innovative at Time 1 showed a mild tendency to experience lower-than-average time pressures at Time 2. Perhaps research management saw the reduction of time constraints as an appropriate way to encourage further creativity. Our data suggest, however, that innovation prospered under time pressure just as did other more routine aspects of scientific performance.

\section{Characteristics of Scientists Who Felt High and Low Time Pressure}

Other data provide insights into the differences between scientists who experienced high and low levels of time pressure and contribute to the validity of the time pressure measure.

Scientists who felt less than average time pressure tended to be rather isolated, free from influence and interference from their supervisor, relatively uninvolved in their work, and with below-average administrative duties. In contrast, those who were highly motivated, in vigorous contact with colleagues and supervisors, and with some administrative responsibilities in addition to their technical work were the ones on whom time pressures impinged the most. (These relationships produced correlations in the range .1 to .5 -data not shown.)

TABLE 3

Correlations among Experienced Time Presstre and Five Other Job Characteristics at Times 1 and $2^{a}$

\begin{tabular}{|c|c|c|c|c|c|}
\hline \multirow[b]{2}{*}{$\begin{array}{l}\text { Job } \\
\text { characteristics }\end{array}$} & \multicolumn{2}{|c|}{$\begin{array}{l}\text { Cross-lagged } \\
\text { relationships }\end{array}$} & \multicolumn{2}{|c|}{$\begin{array}{l}\text { Simultaneous } \\
\text { relationships }\end{array}$} & \multirow{2}{*}{$\begin{array}{c}\begin{array}{c}\text { Stability } \\
\text { relationship }\end{array} \\
\text { Char }_{1} \& \\
\text { Char }_{2}\end{array}$} \\
\hline & $\begin{array}{l}\mathrm{TP}_{1} \& \\
\mathrm{Char}_{2}\end{array}$ & $\begin{array}{l}\mathrm{Char}_{1} \\
\& \mathrm{TP}_{2}\end{array}$ & $\begin{array}{l}\mathrm{TP}_{1} \& \\
\mathrm{Char}_{1}\end{array}$ & $\begin{array}{l}\mathrm{TP}_{2} \& \\
\mathrm{Char}_{2}\end{array}$ & \\
\hline $\begin{array}{l}\text { Freedom provided by } \\
\text { supervisor }\end{array}$ & .06 & -.25 & -.08 & -.19 & .37 \\
\hline $\begin{array}{l}\text { Preferences for work- } \\
\text { ing alone }\end{array}$ & -.38 & -.08 & -.13 & -.31 & .56 \\
\hline $\begin{array}{l}\text { Involvement in } \\
\text { technical work }\end{array}$ & .16 & .03 & .25 & .18 & .66 \\
\hline $\begin{array}{l}\text { Time on administra- } \\
\text { tive duties }\end{array}$ & .40 & .27 & .34 & .19 & .37 \\
\hline $\begin{array}{l}\text { Number of close } \\
\text { colleagues }\end{array}$ & .43 & .48 & .39 & .33 & .51 \\
\hline
\end{tabular}

"See "Method" section for numbers of cases.

${ }^{b}$ For stability of time pressure, see Fig. 1. 
Table 3, which shows cross-lagged analyses for time pressure and these variables, suggests that the provision of freedom by a supervisor may be one cause of a scientist's later feeling under reduced time pressure; on the other hand, time pressure itself seemed to have a causal role in a person's not preferring to work alone. ${ }^{11}$ Although the cross-lagged differentials for work involvement and time on administrative duties did not reach conventional levels of statistical significance, the trends in Table 3 suggest that feelings of work involvement and administrative duties were more likely to result from previous time pressures than was a feeling of time pressure likely to result from them. Finally, although time pressure and the number of close colleagues a person worked with were substantially related, there was no clear evidence that either had causal priority over the other.

Do these results imply that if a supervisor provides freedom for his subordinates their performance will fall? Not necessarily. [In fact, Pelz and Andrews (1966) found that among scientists within the same career level freedom was positively related to scientific performance.] However, if substantial freedom is provided, some additional actions may be required to ensure that scientists stay "hot." We would not want to imply that time pressure is the only motivator, though the results described suggest it may be one important source of motivation.

\section{Other Time Pressure Measures and Performance}

In addition to the time pressure actually experienced by a scientist, the study included three other time pressure measures-the time pressure which the scientists themselves felt would be optimal, the difference between experienced and optimum pressure (one indication of "overload") and the "span" of different pressures experienced during an average month's work. Each of these measures was analyzed in a manner similar to that just described for experienced pressure.

Optimal pressure. Optimal pressure, which itself correlated +.6 with experienced pressure, gave results generally similar to those shown in Figs. 1 and 2 and Table 2. Scientists who wanted above average levels of pressure at Time 1 showed a mild tendency to be the better performers during the following five years ( $r$ 's averaged .22 ). Performance at Time 1 , however, showed weak and inconsistent relationships to time pressure desires five years later ( $r$ 's averaged .02).

${ }^{11}$ In both cases the differences in cross-lagged relationships were highly statistically significant. The items were worded as follows: "My supervisor provides considerable freedom for people under him to explore, discuss, and challenge ideas on their own." "I'm rather a lone wolf; prefer to work on my own." To answer, respondents indicated how accurate the statement was, using a 7 -point scale. 


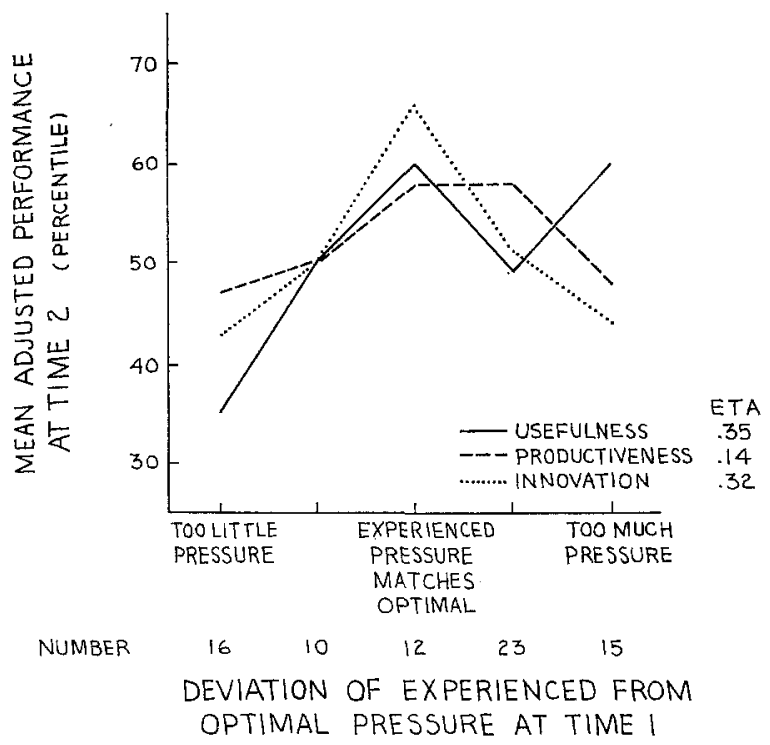

Fig. 3. Mean performance related to time pressure overload.

Overload. The overload measure showed some very interesting curvilinearities. Figure 3 presents the lagged relationships between overload at Time 1 and performance at Time 2. Scientists who had less pressure at Time 1 than they wanted tended to be low performers during the following five years. Those for whom experienced pressure closely matched what they felt would be optimal showed above-average performance in the following period. When pressures exceeded what was desired, subsequent innovation and productivity fell, though usefulness tended to be high. Also of interest was the fact that these lagged relationships (note the ETA's in Fig. 3) were consistently stronger than the comparable simultaneous relationships (not shown). In short, having more time pressure than was desired had more to do with subsequent performance than recent past performance.

These curvilinearities provide an important additional insight into the meaning of the relationships between experienced pressure and performance described previously. While it was true that the higher the pressure, the higher the performance, we now see that this could occur only because the scientists who experienced high pressures also wanted high pressures. Figure 3 shows that being subject to more pressure than was felt appropriate was followed by relatively low innovation and productiveness (but not usefulness). From a practical standpoint, it would appear that laboratory managers must take account of what pressures scientists feel are 
appropriate when setting pressure levels in their labs. Otherwise, the managers may find that they sacrifice some quality in the scientists' work in order to make it more useful to the organization. Of course, managers might also attempt to influence what are seen as appropriate levels of time pressure.

Span. The fourth time pressure measure-the "span" of pressures experienced-showed no interpretable relationships. Performance was unrelated to this aspect of time pressure.

\section{CONCLUSIONS}

Contrary to the folklore which holds that scientists perform best when in a relaxed "academic" environment, these data suggest that a sense of time pressure can enhance several qualities of scientific performance-including innovation. In addition to experiencing the most time pressure, the highest performing scientists also tended to want relatively large amounts of pressure. When the pressure actually experienced was markedly out of line with the pressure desired-either in being too low or too high-performance was likely to suffer. (Exception: excess pressure did not seem to hurt a scientist's judged usefulness to his lab.)

The fact that these findings are based on panel data collected over a five-year interval provides suggestions of causal dynamics not possible when relationships are among variables measured at just a single point in time. At the very least, the findings above represent predictive relationships (time pressure related to subsequent performance), and it seems most unlikely that they result from the spurious effect of some third factor.

Scientists who experienced above average time pressures tended to be those who were in active communication with colleagues, motivated by their jobs, and involved in some administrative duties as well as technical activities. In short, they were well integrated into the social processes of their laboratories. Or, in the language of Kahn et al. (1966), they received expectations from a number of role senders and were more susceptible to role conflict and role overload. The range of role conflict and role overload experienced by the scientists in this study appeared to enhance performance--provided that optimal and experienced time pressures were not greatly out of line.

The implication for management is that the imposition of deadlines and other forms of time pressures need not be feared-at least with respect to their effect on a man's performance-so long as the resulting pressure stays within the bounds of what is felt to be appropriate by the man involved. Some attempt to boost scientist's own desire for time pressures may permit the acceptance of higher pressures. 
However, two cautions need also to be mentioned: (a) although we did not encounter a pressure level that was "too great" among the scientists we studied, there presumably is such a level, and pressures would need to be kept below it; (b) the present study had no information about other effects of pressure (e.g., on physical or mental health). The work of Kahn et al. (1964), Sloate (1969), and French and Caplan (1970) on organizational stress, and of Miller (1960) on information overload, suggests that time pressure may have negative consequences not considered in this study. Further research should clarify relationships between time pressure and other aspects of stress and overload, and consider effects of time pressure on factors other than performance. The present study, combined with the other studies just cited, indicates that different kinds of pressure may have positive as well as negative effects, depending on whether the criterion is performance, long-run organizational effectiveness, or the health of those in stressful situations.

\section{REFERENCES}

Campbell, D. T., \& Stanley, J. C. Experimental and quasi-experimental designs for research on teaching. In N. L. Gage (Ed.), Handbook of research on teaching. Chicago: Rand MeNally, 1963.

Duncas, O. D. Some linear models for two-wave two-variable panel analysis. $P s y-$ chological Bulletin, 1969, 72, 177-182.

FARRIS, G. F. Organizational factors and individual performance: A longitudinal study. Journal of Applied Psychology, 1969, 53, 87-92. (a)

FarRTS, G. F. Some antecedents and consequences of scientific performance. IEEE Transactions on Engineering Management, 1969, EM-16, 9-16. (b)

FArRIs, G. F. Toward a non-experimental method for causal analyses of social phenomena. Australian Journal of Psychology, 1969, 21, 259-276. (c)

FARRIS, G. F. Executive decision making in organizations: Identifying the key men and managing the process. M. I. T. Sloan School of Management Working Paper No. 551-71, 1971.

French, J. R. P., JR., \& Caplan, R. D. Psychosocial factors in coronary heart disease. Industrial Medicine and Surgery, 1970, 39(9), 31-45.

Guilford, J. P. Psychometric methods. New York: McGraw-Hill, 1954.

Hatl, D. T., \& Lawler, E. E., III. Job pressures and research performance. American Scientist, 1971, 59, 61-73.

Heise, D. R. Causal inference from panel data. In E. F. Borgatta (Ed.), Sociological methodology (1970). San Francisco: Jossey-Bass, 1970.

KaHn, R. L., Wolfe, D. M., Quinn, R. P., Snoek, J. D., \& Rosenthal, R. A. Organizational stress: Studies in role conflict and ambiguity. New York: Wiley, 1964.

$\mathrm{K}_{\mathrm{ATZ}}, \mathrm{D} .$, \& $\mathrm{K}_{\mathrm{AHN}}, \mathrm{R} . \mathrm{L}$. The social psychology of organizations. New York: Wiley, 1966.

KenNy, D. A. Testing a model of dynamic causation. Paper presented to the Conference on Structural Equations, University of Wisconsin, November, 1970.

MrLleR, J. G. Information input, overload, and psychopathology. American Journal of Psychiatry, 1960, 116, 513-531. 
Pelz, D. C., \& Andrews, F. M. Detecting causal priorities in panel study data. American Sociological Review, 1964, 29, 836-848.

Pelz, D. C., \& Andrews, F. M. Scientists in organizations: Productive climates for research and development. New York: Wiley, 1966.

Petens, C. C., \& VAN VoonhIs, W. R. Statistical procedures and their mathematical bases. New York: McGraw-Hill, 1940.

ReEs, M. B. A comparison of cross-lagged, path, and multivariate causal inference techniques applied to interest, information, and aspiration among high school students. Unpublished doctoral dissertation, Northwestern University, 1971.

Rozelie, R. M., \& Campberi, D. T. More plausible rival hypotheses in the crosslagged panel correlation technique. Psychological Bulletin, 1969, 71, 74-80.

Sandell, R. G. Note on choosing between competing interpretations of cross-lagged panel correlations. Psychological Bulletin, 1971, 75, 367-368.

SLoAte, A. Termination: The closing at Baker Plant. Indianapolis, Ind.: BobbsMerrill, 1969.

Swarn, R. L. Catalytic colleagues in a government R \& D organization. Unpublished M. S. thesis, Massachusetts Institute of Technology, 1971.

YEE, A. H., \& GAGE, N. L. Techniques for estimating the source and direction of causal influence in panel data. Psychological Bulletin, 1968, 70, 115-126.

RECeIved: September 6, 1971 